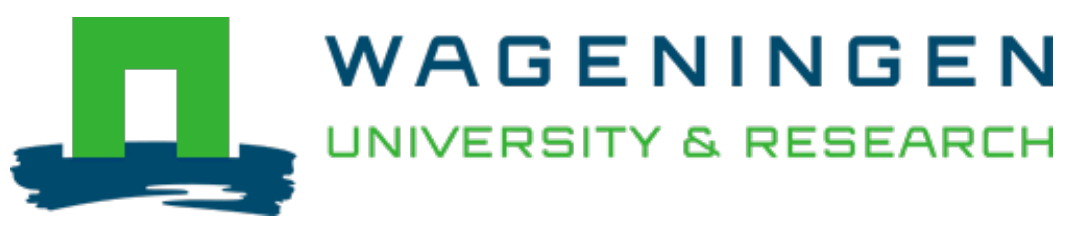

\title{
Obstacles of On-Premise Enterprise Resource Planning Systems and Solution Directions
}

Journal of Computer Information Systems

Sancar Gozukara, Senem; Tekinerdogan, Bedir; Catal, Cagatay

https://doi.org/10.1080/08874417.2020.1739579

This article is made publicly available in the institutional repository of Wageningen University and Research, under the terms of article $25 \mathrm{fa}$ of the Dutch Copyright Act, also known as the Amendment Taverne. This has been done with explicit consent by the author.

Article 25 fa states that the author of a short scientific work funded either wholly or partially by Dutch public funds is entitled to make that work publicly available for no consideration following a reasonable period of time after the work was first published, provided that clear reference is made to the source of the first publication of the work.

This publication is distributed under The Association of Universities in the Netherlands (VSNU) 'Article $25 \mathrm{fa}$ implementation' project. In this project research outputs of researchers employed by Dutch Universities that comply with the legal requirements of Article $25 \mathrm{fa}$ of the Dutch Copyright Act are distributed online and free of cost or other barriers in institutional repositories. Research outputs are distributed six months after their first online publication in the original published version and with proper attribution to the source of the original publication.

You are permitted to download and use the publication for personal purposes. All rights remain with the author(s) and / or copyright owner(s) of this work. Any use of the publication or parts of it other than authorised under article $25 \mathrm{fa}$ of the Dutch Copyright act is prohibited. Wageningen University \& Research and the author(s) of this publication shall not be held responsible or liable for any damages resulting from your (re)use of this publication.

For questions regarding the public availability of this article please contact openscience.library@,wur.nl 


\title{
Obstacles of On-Premise Enterprise Resource Planning Systems and Solution Directions
}

\author{
Senem Sancar Gozukaraa, Bedir Tekinerdogan ${ }^{\mathrm{a}}$, and Cagatay Catal ${ }^{\mathrm{b}}$ \\ a'Wageningen University \& Research, Wageningen, The Netherlands; ${ }^{b}$ Bahcesehir University, Istanbul, Turkey
}

\begin{abstract}
The article presents the results of a Systematic Literature Review (SLR) that has been carried out to identify and present the state-of-the-art of ERP systems, describe the obstacles of on-premise ERP systems, and provide general solutions to tackle these challenges. Based on this SLR, 22 obstacles are identified, the dependencies and interactions among these obstacles are described, and finally the corresponding solutions as described in the primary studies are discussed in detail. Our study shows that there is a general agreement on the obstacles of on-premise ERP systems and further research is needed to provide satisfactory solutions to the obstacles.
\end{abstract}

\section{KEYWORDS}

Enterprise resource planning; systematic literature review; information systems

\section{Introduction}

Enterprise resource planning (ERP) system is a business management system solution which is used for managing, automating, and integrating all the business functions within an organization. ${ }^{1,2}$ ERP system compounds sets of integrated software packages including business tools and applications for product planning, cost and development, manufacturing, inventory management, supply chain, marketing and sales, shipping and payment, human resources, and customer information. ${ }^{3-9}$

ERP system has a shared database which supports multiple functions used by different business units. Using this shared database, an ERP system shares common data and provide access to desired data across the various departments within the organization. ERP systems provide significant benefits for organizations by reducing operating and maintenance costs for information systems, reducing administrative expenses, increasing efficiency of organizational business processes, and increasing quality of information for better decision-making and to better organizational improvement. ${ }^{10-15}$

Various studies have reported on different obstacles with the adoption of on-premise ERP systems. For organizations that wish to adopt ERP systems, it is important to identify these obstacles in order to mitigate the risks and support the careful decision and implementation of the adoption and implementation of the ERP systems. Unfortunately, no explicit survey or review has been published that provide an overview of the key obstacles and their impact on the adoption of on-premise ERP systems. An Systematic Literature Review (SLR) study has been published on the benefits and challenges of cloud ERP systems, ${ }^{16}$ but that paper addressed ERP systems over a cloud computing environment instead of on-premise ERP systems. This article presents the results of an SLR that has been carried out to identify and present the state of the art of on-premise
ERP systems, describe their obstacles, and provide general solutions to tackle these challenges. Sixty-two papers were selected as primary studies from which we derived the answers to the posed research questions. Based on the SLR, 22 obstacles are identified, the dependencies and interactions among these obstacles are described, and finally the corresponding solutions as described in the primary studies are discussed in detail.

This article is organized as follows. Section 2 provides a brief information about ERP Systems. Section 3 describes the SLR method that is used in this study. Section 4 presents the results of the SLR. Section 5 presents and discusses the identified obstacles of on-premise ERP Systems and their proposed solutions. Section 6 presents the overall discussion. Finally, Section 7 concludes the paper.

\section{Background}

Historically, ERP system has evolved from Material Requirements Planning (MRP) ${ }^{17}$ and Material Resource Planning (MRP II) systems. ${ }^{18}$ System integration, flexibility, and accessibility were technical deficiencies of MRP systems. Since MRP systems did not meet the organizational demands, it has been extended from simple material requirement planning software to more complex manufacturing resource planning software (MRP II). ${ }^{18} \mathrm{MRP}$ II is introduced in the 80s as an alternative for MRP. Enhancement of MRP II was followed with the introduction of ERP business software. $^{19}$

Figure 1 shows the reference architecture of on-premise ERP system that has been derived based on the existing literature. Typically, an ERP system has modules for operations and logistics, financials, sales and marketing, and human resources. ${ }^{21}$ The figure aims to show the representative and typical modules of an ERP system. Different support structures such as training, help desk support, online support, and change management support are also used by the organizations to help employees during the 


\section{ON-PREMISE ERP SYSTEM}
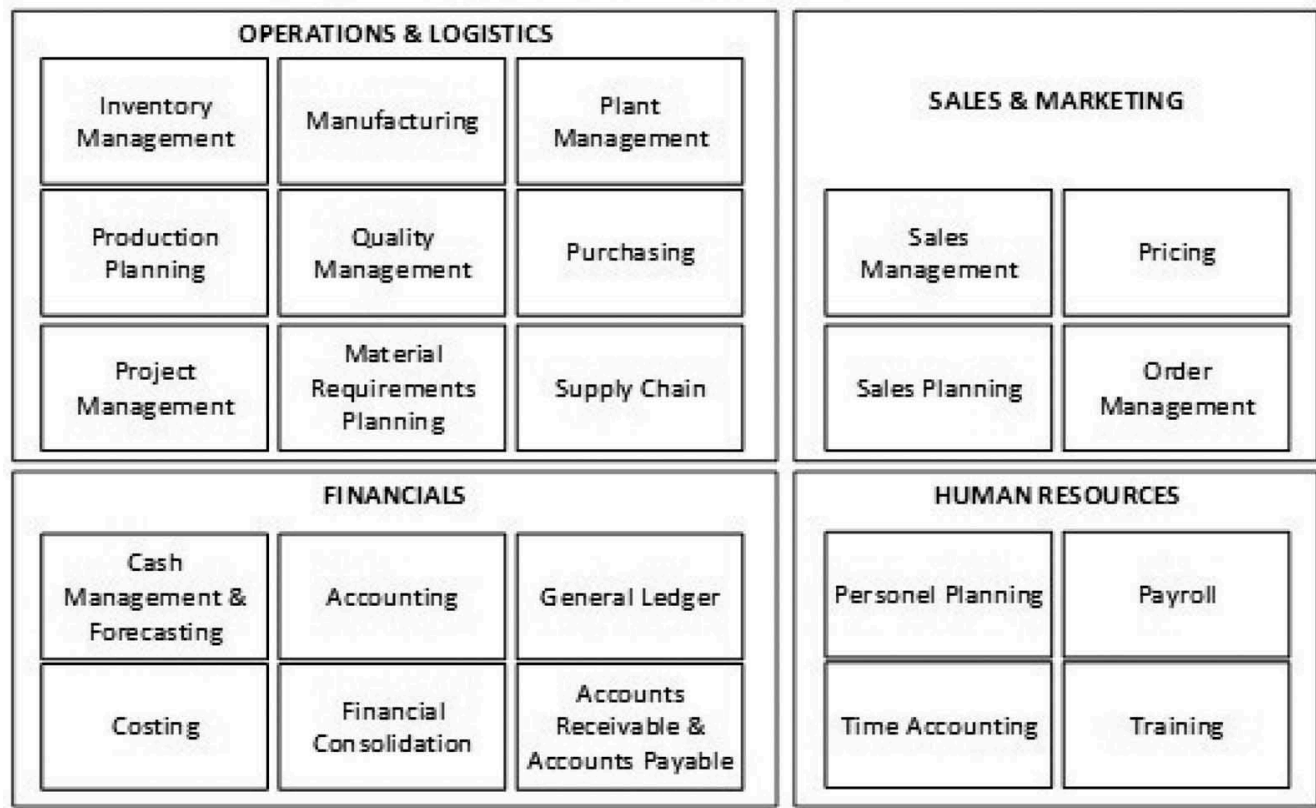

Figure 1. Reference architecture of on-premise ERP systems. ${ }^{20}$

transition phase of these systems. ${ }^{22}$ Several limitations have been identified for the on-premise-based ERP systems. ${ }^{23,24}$

\section{Research method}

For this study, we followed the SLR guidelines proposed by Kitchenham and Charters. ${ }^{25}$

\subsection{Systematic reviews}

An SLR is a method to identify and synthesize relevant studies regarding research questions. ${ }^{25-29}$ There are several reasons for undertaking an SLR including summarizing the existing evidence concerning a technology, identifying any gaps in current research in order to suggest areas for further investigation, or assisting in the generation of new hypotheses. ${ }^{30-34}$

\subsection{Review protocol}

A review protocol is required for conducting SLR study, ${ }^{35,36}$ and therefore we first defined our review protocol which includes several relevant steps.

Our review protocol is depicted in Figure 2 which shows all the steps of our review protocol. During the search strategy definition step, we applied the approach of Zhang et al. ${ }^{37}$ which helped us to clarify the search space.

\subsection{Research questions}

We aimed at the current state-of-the-art by means of our research questions with a wide sphere of influence in order to get the best evidence. ${ }^{25,38}$ The research questions are formulated as follows:

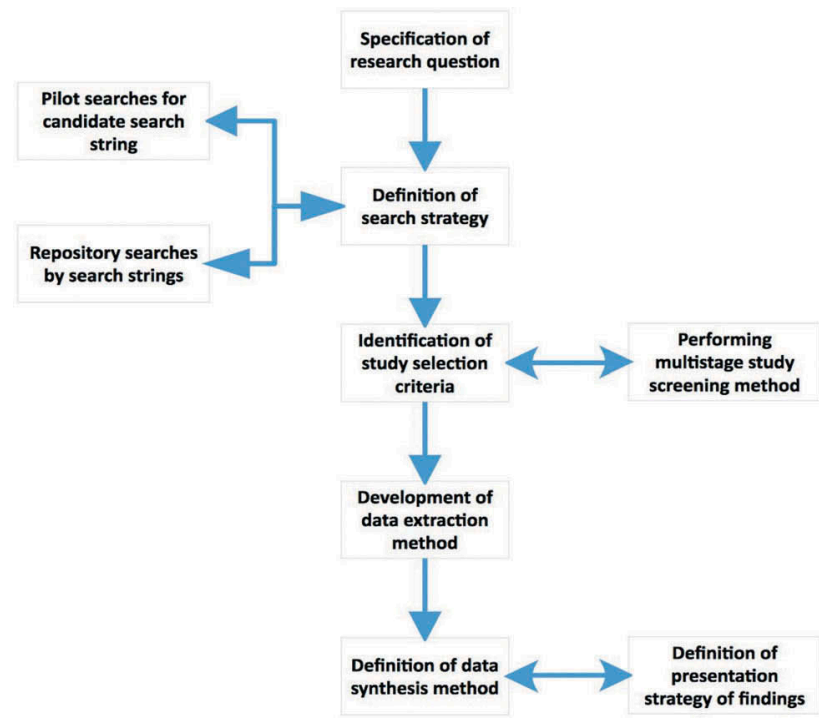

Figure 2. Steps of our review protocol.

- RQ1: What are the identified obstacles of on-premise ERP systems?

- RQ2: What are the relations between identified obstacles of ERP systems?

- RQ3: What are the provided solution directions for coping with the obstacles of on-premise ERP systems?

\subsection{Search strategy}

To answer the research questions, we performed an extensive search of studies. We used the following databases and search engines listed in Table 1. 
Table 1. Identified number of papers in the selected databases.

\begin{tabular}{lcc}
\hline Database & Number of Papers After Query & Number of Papers after EC \\
\hline Web of Science & 61 & 10 \\
Scopus & 157 & 22 \\
ACM Digital & 234 & 6 \\
Science Direct & 20 & 24 \\
Total & 472 & 62 \\
\hline
\end{tabular}

In this study, we carried out a manual search to specify proper search strings, and then, we used the resulting search strings to find the optimal results. ${ }^{37,39}$ In the determination of the research question listing of synonyms, abbreviations, and alternative spellings are also considered. Hereafter, a multifaceted search string could be obtained by means of Boolean ANDs and ORs. The search string obtained for this study is shown as follows:

("obstacles" OR "problems" OR "disadvantages" OR "drawbacks") AND ("on-premise" OR "onpremise" OR "traditional") AND ("ERP" OR "ERP System" OR "Enterprise Resource Planning System")

\subsection{Study selection criteria}

The overall exclusion criteria that we used were as follows: ${ }^{25}$

- Do not relate to ERP;

- Do not state any ERP problems or ERP-related problems;

- Do not report any results on the earnings of the approach proposed;

- Abstracts or titles that do not mainly discuss the provision of ERP were excluded;

- Abstracts or titles that do not propose an approach for ERP systems that we have discussed were excluded.

We performed manual analysis for controlling the exclusion criteria, then after applying the exclusion criteria, 62 papers remained.

\subsection{Study quality assessment}

All the identified papers were assessed for quality. The following quality criteria which were adapted from Kitchenham et al. $^{40}$ were applied. These questions were answered based on the following scale (yes $=1$, no $=0$, somewhat $=0.5$ ). Studies with a score lower than 4 are excluded from this SLR study to maintain the quality. The quality assessment scores for the papers are shown in Figure 3.

- Q1: Are the aims of the study clearly stated?

- Q2: Are the scope and experimental design of the study defined clearly?

- Q3: Are the variables in the study likely to be valid and reliable?

- Q4: Is the research process documented adequately?

- Q5: Are all the study questions answered?

- Q6: Are the negative findings presented?

- Q7: Are the main findings regarding creditability, validity, and reliability stated?

- Q8: Do the conclusions relate to the aim of purpose of the study?

\subsection{Data extraction}

To record the relevant information from the identified papers, each paper was read the full text by authors. Data extraction form was used to gather this information. In addition to the basic data such as publication date, the form included columns regarding the research questions.

\subsection{Data synthesis}

In this step, extracted data are summarized in such a way that research questions can be answered. Not only the qualitative synthesis was performed but also quantitative synthesis was realized.

\section{Overview of selected studies}

In this section, we present the distribution of the number of primary studies as yearly basis that they were published in.

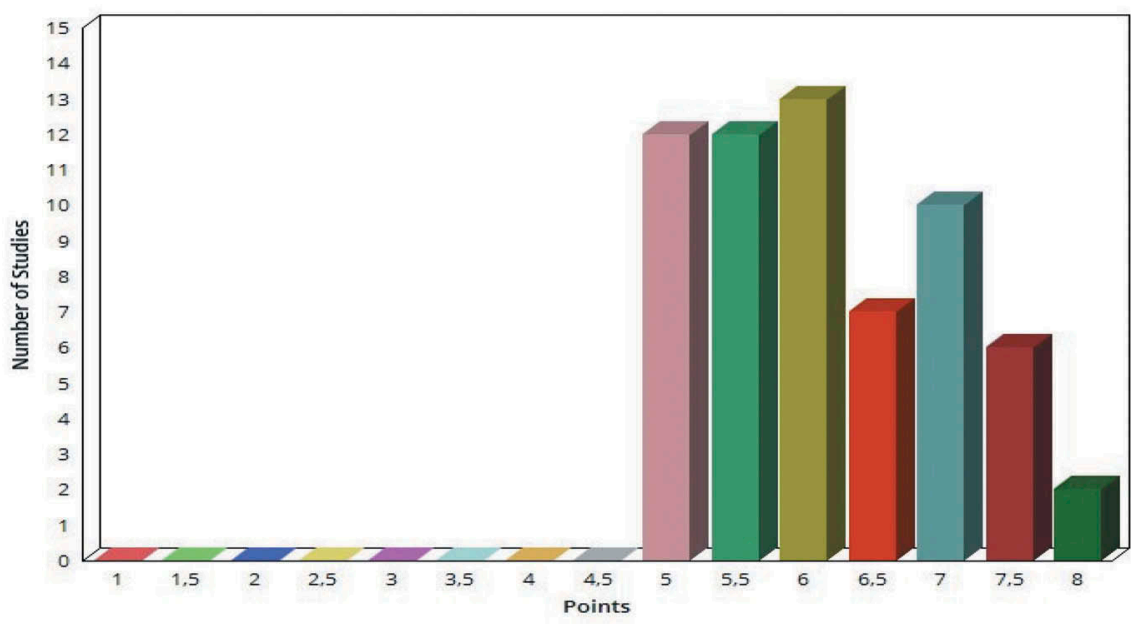

Figure 3. Quality score distribution for the identified papers. 


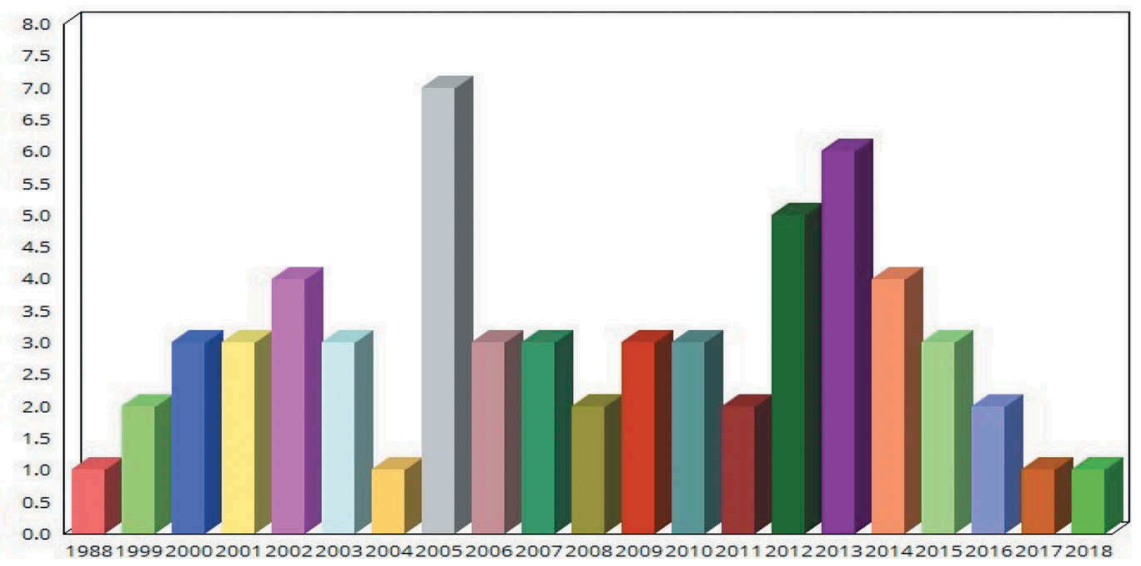

Figure 4. Annual basis distribution of primary studies.

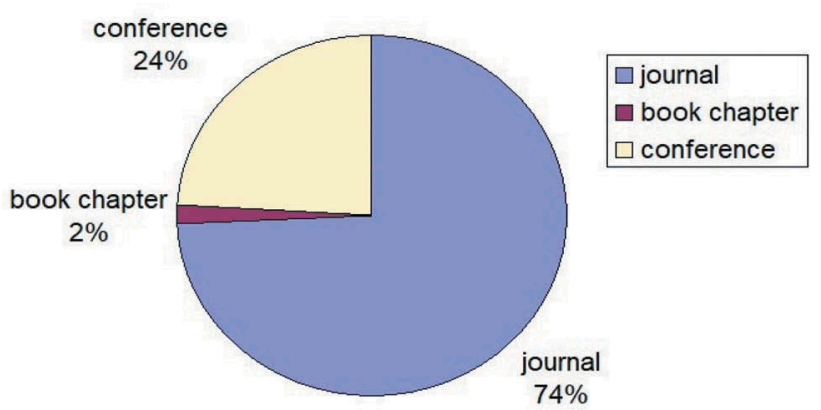

Figure 5. Distribution of papers in terms of publication channel.

Figure 4 shows the year-wise distribution of primary studies. From this figure, we can derive that there has been a continued interest on the obstacles of ERP systems. An overview of the primary studies according to publication channels is shown in Figure 5. From this figure, we can see that most of the studies were published in journals and the remaining was published in conference proceedings.

\section{Identified obstacles and solutions}

This section outlines the results we extracted related to three research questions. We present the data extracted from primary studies separately for each question.

\subsection{Identified obstacles of on-premise ERP systems}

The identified obstacles of ERP Systems are described in this section by answering the first research question (RQ1). We have adopted the so-called BAPO (Business, Process, Architecture, and Organization) framework ${ }^{41}$ for classifying the obstacles. The list of obstacles is shown in Table 2.

\section{P1. Large upfront financial investment}

On-Premise ERP systems require large upfront investments. Also, after implementation, on-premise ERP systems require large amount of investments for system maintenance, configuration, and software updates $[R]$. Organizational cost overruns due to the adoption of an ERP system can be seen as an obstacle in front of a successful ERP implementation [CC]. From the aspect of developing countries, organizations cannot afford high initial costs of ERP systems which results with low ERP adoption [B, D, K, P]. Also, investments for ERP system implementation are more affordable for larger size organizations $[\mathrm{B}]$.

\section{P2. Conflict of interest}

ERP implementations might result in conflict of interests between customer organizations and service provider ERP vendors. While organizations expect unique business solutions from ERP system for their organizational business processes, ERP vendors offer generic solutions applicable for general market. Conflict of interests between customers and ERP vendors affects the success of an ERP implementation and generally leads to the required ERP customization [A]. ERP vendors prefer standardized solutions and present generic solutions to organizations [E]. Standardized and generic ERP systems require huge storage and broad network infrastructure in order to satisfy wide range of organizations. This situation results in customer dissatisfaction due to the required scale of business re-engineering in business processes [E].

\section{P3. Adaptation of business process to evolving ERP modules}

The alignment of organizational business processes to the introduced ERP system is not trivial and can affect the success of an ERP system [X]. Typically, the alignment can require the customization of the business processes [JJ]. Since the ERP modules are closely related, customization might affect soon multiple modules and require additional costs, which on its turn increase the required investments $[R]$.

\section{P4. Vendor lock-in}

Dependency on ERP vendors and consultants is an obstacle for the success of on-premise ERP systems [N]. An ERP system requires new IT skills for the organization, system users need to get support, organizations need to fix ERP problems and need to upgrade the system to latest versions to increase ERP system's performance and to get benefit from an ERP system. Study [W] states the importance of relationship and knowledge management, by emphasizing the need for sufficient skilled internal staff. 
Table 2. On-premise ERP problems.

\begin{tabular}{|c|c|c|}
\hline Category & Problem (RQ1) & References in Appendix \\
\hline Business & P1. Large upfront financial investment & $\begin{array}{l}\mathrm{B}, \mathrm{D}, \mathrm{K}, \mathrm{P}, \mathrm{R}, \\
\mathrm{CC}, \mathrm{MM}, \mathrm{XX} \\
\mathrm{HHH}\end{array}$ \\
\hline Business & P2. Conflict-of-Interest & $\mathrm{A}, \mathrm{E}$ \\
\hline Business & P3. Adaptation of Business Process to Evolving ERP Modules & $\mathrm{R}, \mathrm{X}, \mathrm{J} J, \mathrm{NN}$ \\
\hline Business & P4. Vendor Lock in & N,W,MM \\
\hline Business \& Architecture & P5. Lack of alignment between Business Processes and ERP & $\mathrm{G}, \mathrm{H}, \mathrm{P}, \mathrm{PP}$, \\
\hline & System & $\mathrm{RR}, \mathrm{VV}, \mathrm{YY}$ \\
\hline Business & P6. Difficult to Measure and Meet Return on Investment & $\mathrm{E}, \mathrm{M}, \mathrm{V}$ \\
\hline Architecture & P7. Long implementation Time and Time to Market & C,T,CC \\
\hline Architecture & P8. Resistance compromising business process to align with generic ERP Modules & $\mathrm{F}$ \\
\hline Architecture & P9. Lack of Expressiveness of ERP & $\mathrm{F}$ \\
\hline Architecture & P10. Complexity of ERP Software & $\mathrm{G}, \mathrm{LL}, \mathrm{YY}, \mathrm{HHH}$ \\
\hline Process & P11. Lack of Change Management of ERP Modules and Business Processes & $\begin{array}{l}\text { J,S,Z,CC,HH } \\
\text { VV,KKK }\end{array}$ \\
\hline Process & P12. Testing of ERP Modules & G \\
\hline Process & P13. Difficulty in identifying the required features for the Targeted ERP System & Q \\
\hline Process & P14. Lack of Decent Project Management & $\begin{array}{l}\mathrm{H}, \mathrm{LL}, \mathrm{DDD}, \\
\mathrm{EEE}, \mathrm{JJJ}\end{array}$ \\
\hline Organization & P15. Learning Curve & $\mathrm{G}, \mathrm{H}$ \\
\hline Organization & P16. Lack of in-House Skills & $\begin{array}{l}\text { G,I,AA,FF, } \\
\text { OO,RR,TT, WW,CCC }\end{array}$ \\
\hline Organization & P17. Lack of Balanced Project Team & $\mathrm{H}, \mathrm{J}$ \\
\hline Organization & P18. Organizational Misfit (Cultural Unity) (Impact of Cultural Concerns) & $\begin{array}{l}\text { A,D,M,V,LL, } \\
S S, X X, Z Z\end{array}$ \\
\hline Organization & P19. Lack of Management Support & $\begin{array}{l}\text { BBB,HHH, III } \\
\text { J,M,HH,KK,LL, VV,AAA,BBB, } \\
\text { FFF,GGG,HHH }\end{array}$ \\
\hline Organization & P20. Resistance to Adoption of ERP & $\mathrm{G}, \mathrm{H}, \mathrm{U}, \mathrm{DD}, \mathrm{JJJ}$ \\
\hline Organization & P21. Relative Invisibility & $\mathrm{L}, \mathrm{N}, \mathrm{O}, \mathrm{UU}$ \\
\hline Organization & P22. Loss of Control Due to Decentralized Decision Making & G \\
\hline
\end{tabular}

\section{P5. Lack of alignment between business processes and ERP system}

ERP systems are implemented in organizations with the aim to improve business processes and improve profit of organization [G]. Lack of alignment between organizational business processes and the ERP system is a vital obstacle for the success of ERP implementation. Inconsistencies between business processes and ERP system's logic result with an establishment of an ERP system which might not meet organizational requirements $[\mathrm{P}]$. Another reason for lack of alignment between business processes and ERP system is the lack of detailed requirement specification before implementation of an ERP system [H].

\section{P6. Difficult to measure and meet return on investment}

Uncovered return on investment (ROI) of ERP system is considered as an important financial obstacle for ERP system implementation. According to $[\mathrm{E}]$, most of the organizations spend 3-7 times more money for the implementation and maintenance of an ERP system when compared with a purchasing of the software license. ERP system is required to fully operate before providing benefits and effectiveness to the organizational processes. [V] also mentions that in short run, ERP system implementation does not increase income by increasing sales or reducing costs, but ERP provides benefits in the long term.

\section{P7. Long implementation time and time to market}

On-premise ERP systems require long implementation time, which consequences with longer time to market for providing new features for specific business processes and this situation affects organizational performance and ROI by extending time to market of their services and products [CC]. In order to implement an ERP system that meets the necessary requirements, great amount of time and emphasis are needed to clarify the organizational strategy, current situation, and expectations of the organization [T]. Another problem that arises with long implementation time is longer waiting periods for ROI [C].

\section{P8. Resistance compromising business process to align with generic ERP modules (Customization)}

The adoption of generic ERP modules is considered as one of the most important obstacles for on-premise ERP systems. In order to meet general needs of organizations, ERP software is implemented with core business functions, which are generic market solutions and they do not meet the unique requirements of every organization [F]. Although customized ERP systems provide services for specific organizations, without further support and continuous maintenance, for an ERP system, it is hard to provide appropriate services to the organizations $[\mathrm{F}]$.

\section{P9. Lack of expressiveness of ERP/need for dedicated modules}

Existing ERP modules are generic and can be customized to meet the business requirements. Besides generic ERP modules, some ERP modules are developed to come out solutions for different industries in order to adapt different organizational business processes. However, for very specific cases, the ERP modules might fail short to express the corresponding needs. Even if a generic ERP system is customized to satisfy organizations' requirements and adapted with business processes of specific organizations, it might not fit to every single manufacturing plant of the organization [F]. 


\section{P10. Complexity of ERP software}

Implementation of this complex software requires large investments for purchasing of the hardware and software, implementation costs, and user training costs [G]. Since ERP is a complex software, user experience is important for the effective use of this system. Also, a sound system configuration is crucial for a high-quality ERP implementation [LL].

\section{P11. Lack of change management of ERP modules and business processes}

The implementation of an ERP system brings an organization to large-scale change that the change leads to confusion and resistance among employees if it is not managed effectively [S]. The lack of a change management process in an organization is also a vital obstacle for the success of ERP systems [J, $\mathrm{CC}, \mathrm{HH}]$. Most ERP implementations fail since companies underestimate the importance of change management [S]. Lacking change management process results with untraceable changes in ERP modules [Z].

\section{P12. Testing of ERP modules}

Deficiency of ERP module testing after system implementation is a crucial mistake for the success of an ERP system that may result with incompatibilities between operational business processes and ERP operations. Inadequate testing and monitoring of ERP modules increases risks associated with the lack of adaptability between ERP system and organization's business processes [G].

\section{P13. Difficulty in identifying the required features for the targeted ERP system}

In ERP adoption process, the most important obstacle for organizations is the adoption of the common ERP system without considering tailor-made objectives and proper requirements that reflect organization's distinguishing features [Q]. Configuration tables include features for selecting ERP modules which may satisfy the specific objectives and requirements of organizations.

\section{P14. Lack of decent project management in ERP implementation}

In order to implement a successful ERP system and get benefit this ERP system, implementation project should be managed carefully [LL]. Lack of project management skills during ERP implementation phase may come up with problems in system's operation since business processes and ERP system integration should be engaged, then processes should be operated with ERP system [H].

\section{P15. Learning curve}

Steep learning curve may be considered as an obstacle on the effective use of ERP system. Ineffective use of an ERP system results with the failure in business processes which is an inexpedient situation, waste of time, and waste of money for organizations. Managers can get experience in ERP system during the implementation process and transfer their knowledge to system users in the organization which accelerates users' learning processes [G]. System users cannot get adequate training regarding ERP system at early stages of ERP implementation project $[\mathrm{H}]$. The lack of proper training poses a crucial obstacle on the system users learning curve. ${ }^{42}$

\section{P16. Lack of in-house skills}

Inexperienced personnel who is lacking in-house skills can be considered as a major obstacle for the success of ERP systems in organizations. Also, ERP implementation project requires knowledge about organizational business processes, organizational structure, risk management, and change management [G]. Ignorant system users who are having problems to transfer their organizational knowledge to ERP vendors cannot manage to corporate with ERP implementation team [I]. Study [AA] also emphasizes the importance of ERP adoption factors, especially in developing economies and in SMEs. Study [FF] also mentions about the difficulties of ERP implementation for SMEs by emphasizing the limited number of system users.

\section{P17. Lack of balanced project team}

Unbalanced project team is a critical obstacle for the success of an ERP implementation. ERP implementation is performed by staff who have technical knowledge and supported by ERP consultants. However, inadequate knowledge of technical staff about existing business processes and operations of an organization poses an important obstacle for the success of an ERP system [J, H].

\section{P18. Organizational misfit (Cultural unity) (Impact of cultural concerns on implementation and adaptation of ERP modules)}

Difference in interest between organizations and ERP vendors is considered as an obstacle on the implementation of on-premise ERP. Differences in interests incline the emergence of organizational misfit perspective for on-premise ERP implementation [A]. Studies [A] and [D] state that organizational culture directly affects organizational processes. Organizational business processes in Asia are quite different form the business processes in Europe and USA [M]. Similarly, study [V] mentions about the management culture of organizations in Asia. Differences in organizational structures and managerial point of views between different cultures pose obstacles on the implementation and adoption of on-premise ERP [M, LL].

\section{P19. Lack of management support}

Lack of management support is considered as an obstacle for the success of an ERP system both in the implementation phase and the operation phase [KK]. Top management support is critical for early stages of ERP implementation projects $[\mathrm{HH}, \mathrm{M}]$. In case of lack of management support, business requirements might not be defined clearly, and necessary resources cannot be provided easily [J]. Study [LL] discusses the benefits of leadership involvement for the postimplementation success and presents justifications for the effects of leadership involvement.

\section{P20. Resistance to adoption of ERP (Lack of user support and user resistance)}

Lack of user support is an important obstacle for on-premise ERP systems. System development is affected by different factors such as the complexity of application, experiences of 
system users, and expertise levels of system users [G, DD]. Expertise level of users affects the success and the performance of on-premise ERP system [G]. Study [U] also states that ERP system requires changes after the implementation and this situation might result in more significant user resistance within organizations. During the early stage of the ERP implementation, there is lack of awareness of the ERP system $[\mathrm{H}]$.

\section{P21. Relative invisibility}

Invisible and unpredictable interactions are identified as obstacles for on-premise ERP systems. Study [L] mentions relative invisibility as a major cause of on-premise ERP failure. For continued improvements on ERP system, many organizations depend on ERP vendors [N]. For instance, study [O] states that there is a FoxMeyer case that they did not realize that the project was in trouble at the beginning. Their dependencies on consultants and vendors prevented them from seeing how to gain control over their own ERP systems.

\section{P22. Loss of control due to decentralized decision-making} Loss of control over ERP implementation project is an important obstacle for the success of ERP systems. Organizations which decide to implement ERP system organize ERP implementation team by considering individuals' specific knowledge associated with ERP implementation such as their technical knowledge. However, when the team becomes fully responsible, there exists no approval mechanism for projectrelated decisions.

Decentralization of decision-making process during ERP project causes the loss of control over ERP project team, which results in the failure of ERP system [G].

\subsection{Relationship between identified problems}

Twenty-two obstacles identified for on-premise ERP systems are not independent and are related to each other. These relations are visualized in Figure 6. The problems with a larger number of outgoing arrows can be considered as problems that form the basis for and trigger other problems. Problems with many incoming arrows are typically the problems that are triggered by other problems. Altogether, the number of problems for adopting ERP systems seems indeed very complex.

\subsection{General solutions for ERP systems}

The selected primary studies helped to identify the obstacles, but often provided the solution directions for coping with these obstacles. These are listed in Table 3.

\section{S1. For P1 Large upfront financial investment}

Concerns of organizations about the high amount of initial investments for on-premise ERP system cannot be avoided. However, for the long term, the upfront investment can be reduced later. During the implementation period, working of internal staff along with each ERP consultant increases the knowledge of internal staff [W]. Newly trained internal staff can operate and perform the maintenance of ERP system and cash on the firm financially.

\section{S2. For P2 conflict of interest}

The problem of conflict of interests between customer organizations and service provider ERP vendors arises from the vendors fall short of the expectations of their customers. To meet expectations and satisfy customer organizations, ERP vendor should provide specific solutions to their customers

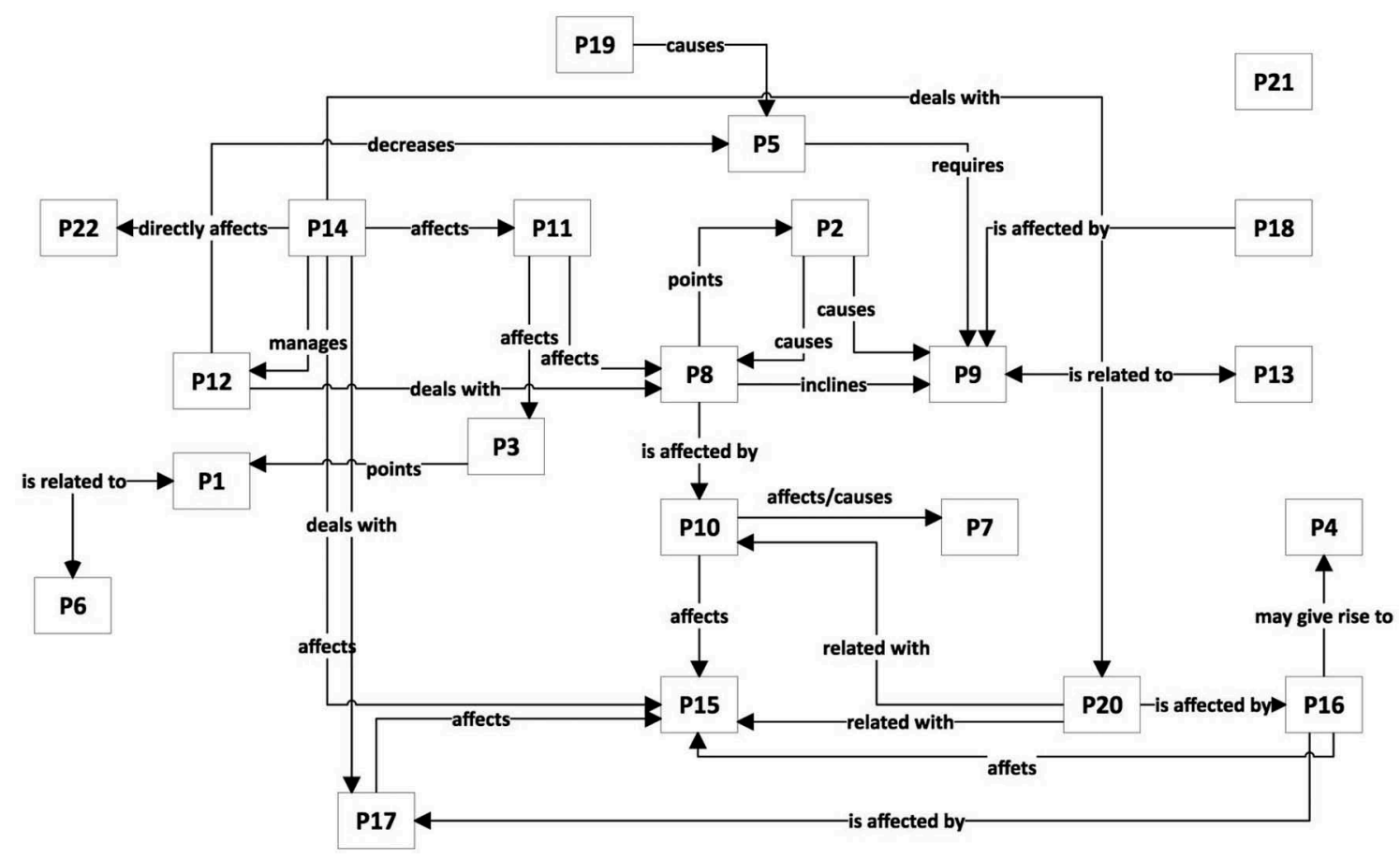

Figure 6. Relation between identified problems of on-premise ERP systems. 
Table 3. General solutions for On-premise ERP problems.

\begin{tabular}{|c|c|c|c|}
\hline Category & Problem (RQ1) & General solution (RQ2.1) & Ref \\
\hline Business & P1. Large upfront financial investment & $\begin{array}{l}\text { *Provide a lighter version of the ERP }{ }^{*} \text { Adopt common license } \\
{ }^{*} \text { Educated internal staff }\end{array}$ & W \\
\hline Business & P2. Conflict-of-Interest & ${ }^{*}$ Specific solutions for customers *ERP extensions & $\mathrm{G}, \mathrm{E}$ \\
\hline Business & $\begin{array}{l}\text { P3. Adaptation of Business Process to } \\
\text { Evolving ERP Modules }\end{array}$ & $\begin{array}{l}\text { *Customization of an ERP system *Modification of organizational business } \\
\text { processes *Using business process re-engineering tool }\end{array}$ & $X, Y$ \\
\hline Business & P4. Vendor Lock in & $\begin{array}{l}\text { *Training system users and improving knowledge of ERP system within } \\
\text { organization *Using in-house skills *Working close with external ERP } \\
\text { consultants during implementation }\end{array}$ & $\mathrm{G}, \mathrm{N}, \mathrm{W}$ \\
\hline Business \& Architecture & $\begin{array}{l}\text { P5. Lack of alignment between } \\
\text { Business Processes and ERP System }\end{array}$ & $\begin{array}{l}\text { *Well-designed organizational business processes \& well- } \\
\text { defined requirements }\end{array}$ & $\mathrm{G}, \mathrm{H}, \mathrm{X}, \mathrm{GG}$ \\
\hline Business & $\begin{array}{l}\text { P6. Difficult to Measure and } \\
\text { Meet Return on Investment }\end{array}$ & ${ }^{*}$ Get benefit from a few months later ${ }^{*}$ Focus on reuse & $\mathrm{C}, \mathrm{E}, \mathrm{M}$ \\
\hline Architecture & $\begin{array}{l}\text { P7. Longimplementation } \\
\text { Time and Time to Market }\end{array}$ & $\begin{array}{l}\text { *Focus on accelerated ERP implementation approach(an ERP packed) then } \\
\text { traditional one }\end{array}$ & $\mathrm{T}$ \\
\hline Architecture & $\begin{array}{l}\text { P8. Resistance compromising business } \\
\text { process to align with generic ERP } \\
\text { Modules }\end{array}$ & - No specific solution is provided & $\mathrm{F}$ \\
\hline Architecture & $\begin{array}{l}\text { P9. Lack of Expressiveness of ERP/ } \\
\text { Need for Dedicated Modules }\end{array}$ & ${ }^{*}$ Modifications of generic ERP packages *Use of bolt-on modules & $\mathrm{F}$ \\
\hline $\begin{array}{l}\text { Architecture \& } \\
\text { Organization }\end{array}$ & P10. Complexity of ERP Software & $\begin{array}{l}\text { *Direct involvement of top management to implementation *Top } \\
\text { management's contribution *Trained users }\end{array}$ & G \\
\hline Process & $\begin{array}{l}\text { P11. Lack of Change Management of } \\
\text { ERP Modules and Business Processes }\end{array}$ & $\begin{array}{l}\text { *Effective change management process *Traceable change management } \\
{ }^{*} \text { Change of organizational BPs and way of business performed }\end{array}$ & $\mathrm{S}$ \\
\hline Process & P12. Testing of ERP Modules & *Testing each ERP module according to related business process & G \\
\hline Process & $\begin{array}{l}\text { P13. Difficulty in identifying the } \\
\text { required features for the Targeted ERP } \\
\text { System }\end{array}$ & *Specifyingorganizational needs and identifying expected features & Q \\
\hline Process & $\begin{array}{l}\text { P14. Lack of Decent Project } \\
\text { Management in ERP Implementation }\end{array}$ & $\begin{array}{l}\text { *Establishment of a project management unit }{ }^{*} \text { Adequate project team } \\
{ }^{*} \text { Keep track of changes in business processes }\end{array}$ & $\mathrm{H}$ \\
\hline Organization & P15. Learning Curve & $\begin{array}{l}\text { *Implementation team, mixed of internal staff and consultants *Provide } \\
\text { ERP consultants' knowledge to system users *Early system training }\end{array}$ & $\mathrm{G}, \mathrm{H}$ \\
\hline Organization & P16. Lack of in-House Skills & $\begin{array}{l}\text { *On-the-job training for system users *User involvement during system } \\
\text { implementation }\end{array}$ & $\mathrm{G}, \mathrm{I}$ \\
\hline Organization & $\begin{array}{l}\text { P17. LackofBalanced } \\
\text { Project Team }\end{array}$ & $\begin{array}{l}\text { *Mixture of an implementation team, internal staff, system users \& } \\
\text { technical ERP consultants }\end{array}$ & $\mathrm{H}, \mathrm{J}$ \\
\hline Organization & $\begin{array}{l}\text { P18. Organizational Misfit (Cultural } \\
\text { Unity) }\end{array}$ & $\begin{array}{l}\text { *Providing more specific and divisional ERP solutions } \\
\text { *Knowledge about organizational culture, structures of non-European } \\
\text { organizations }\end{array}$ & $A, D, M$ \\
\hline Organization & $\begin{array}{l}\text { P19. Lack of Management } \\
\text { Support }\end{array}$ & *Top management involvement to ERP implementation process & $\mathrm{J}, \mathrm{M}, \mathrm{AA}, \mathrm{CC}$ \\
\hline Organization & $\begin{array}{l}\text { P20. Resistance to Adoption of ERP } \\
\text { (Lack of User Support and User } \\
\text { Resistance) }\end{array}$ & $\begin{array}{l}\text { *Understanding of needs of system users } \\
\text { *Clarifying roles and responsibilities of system users } \\
\text { *Providing top management support *Training ERP system users Taking } \\
\text { user resistance as feedbacks for ERP implementation }\end{array}$ & $\mathrm{G}, \mathrm{H}, \mathrm{U}$ \\
\hline Organization & P21. Relative Invisibility & ${ }^{*}$ No specific solution is provided & - \\
\hline Organization & $\begin{array}{l}\text { P22. Loss of Control Due to } \\
\text { Decentralized Decision-Making }\end{array}$ & $\begin{array}{l}\text { *Involvement of top management to ERP implementation project } \\
\text { *Formulation of a proper project steering committee } \\
\text { *Designation of a sponsor } \\
{ }^{*} \text { Conducting audits }\end{array}$ & G \\
\hline
\end{tabular}

[G]. In order to fill the gap between the ERP system's functionality and organizational requirements, vendors might provide ERP extensions [E]. ERP vendors could modify the source code of ERP systems and offer specific solutions. Modification results ERP solutions that result with the satisfaction of customer organizations and solve the problem [E].

\section{S3. For P3 adaptation of business process to evolving ERP modules}

The problem of adoption of business processes to evolving ERP system can be solved either by customization of an ERP system or modification of business processes. Since the customization is expensive and difficult, usually it is necessary to meet the requirements of specific business processes. Study $[\mathrm{X}]$ indicates the importance of re-engineering of organizational business processes for the success of an ERP system. Study [Y] also emphasizes the importance of the business processes re-engineering of current processes to designing new ones.

\section{S4. For P4 vendor lock-in}

ERP is a complex software which requires expertise, especially in the implementation and proper maintenance of the system. Therefore, to have a prospering ERP system, organizations easily get locked into ERP vendors and consultants who have expertise in implementing and maintaining ERP systems [N]. If organizations have educated system users and adequate knowledge about ERP system, they do not need only rely on external ERP implementation teams and consultants [G]. Study [W] states the importance of knowledge transfer between ERP vendors/consultants implementing ERP system and internal staff. According to [W], organizations need to provide as many of internal staff as the ERP vendors/consultants demanded to implement and operate ERP system successfully.

\section{S5. For P5 lack of alignment between business processes and ERP system}

Harmony between organizational business processes and ERP system is considered as the most important success factor for 
ERP system implementation [G]. Successful ERP system improves business processes, and improved business processes increase the profit of organization [G]. The development of requirements will substantially solve the problem of inconsistencies between business processes and ERP system. The involvement of end users to the ERP system implementation project during development and implementation stages is important for the success of an ERP system [H]. Study [GG] also emphasizes the importance of user participation in the early stages of ERP implementation.

\section{S6. For P6 difficult to measure and meet return on investment}

Uncovered return on investment of ERP system is considered as an important financial obstacle for ERP system implementation. According to [E], most of the organizations spend 3-7 times more money for the implementation and maintenance of an ERP system compared to a purchasing of the software license. ERP system is required to fully operate before providing benefits and effectiveness to the organizational processes. Study $[\mathrm{M}]$ proposes to conduct a survey about getting benefits of ERP systems. Study [C] makes a comparison between ERP adopter and non-adopter organizations.

\section{S7. For P7 long implementation time and time to market}

On-premise ERP systems also require long system implementation time, which means long time to market. The problem of long implementation time can be solved by choosing an accelerated implementation approach instead of traditional implementation approach. The accelerated ERP implementation approach gives advantage of speed in ERP implementation and solves the problem of long implementation time and time to market $[\mathrm{T}]$.

\section{S8. For P8S.1 resistance compromising business process to align with generic ERP modules (customization)}

The adoption of an organization's business processes to ERP system might be possible with the tailoring of generic ERP modules to fit specific business processes. Specific ERP solutions might reduce the resistance between organizational business processes and an ERP system. However, ERP vendors and implementation consultants put up resistance for software code changes. Although customized ERP system provides services for specific organizations, without further support and continuous maintenance, for an ERP system, it is hard to provide appropriate services to the organizations $[\mathrm{F}]$.

\section{S9. For P9 lack of expressiveness of ERP/need for dedicated modules}

Generic ERP modules cannot meet specific requirements, therefore they are customized to satisfy organization's needs and to fit organizational processes. However, for very specific cases, the ERP modules might fail short to express corresponding needs. In this case, in parallel to the ERP modules, novel dedicated modules need to be implemented. This on its turn however will require additional time, and as such reduce productivity, enhances complexity, and increase maintenance efforts. In order to solve lack of expressiveness problem and to fit ERP system to the organizational business processes, extensive modifications are performed to ERP system [F].

\section{S10. For P10 complexity of ERP software}

ERP is a complex software, though organizations should consider and cope with this complexity by assigning senior managers to ERP system implementation project through all phases. Direct involvement of top management to the ERP system implementation affects the success of the project and helps to solve the complexity problem of the system [G].

\section{S11. For P11 lack of change management of ERP modules and business processes}

By ensuring an effective change management process, organizations could trace the ERP system required changes decently by keeping their logs. Organizations become successful in the implementation of ERP system by changing their business processes and changing the way of business they do. An effective change management process also helps to reduce the confusion of employees and helps to decrease the resistance of employees to the new ERP system $[\mathrm{S}]$.

\section{S12. For P12 testing of ERP modules}

Neglecting to test ERP modules after implementation might result in losing sight of incompatibilities between organizational business processes and ERP system operations and can cause the failure of an ERP system. Adequate testing and monitoring of ERP modules decrease the risks associated with the in-adaptability problem between ERP system and organizations' business processes [G].

\section{S13. For P13 Difficulty in identifying the required features for the targeted ERP system}

The problem of the adoption of common ERP system without considering tailor-made objectives for specific organizations and without considering proper requirements which reflects organizations' needs can be solved by forming an ERP project team which collects necessary requirements of the organization and by considering an ERP systems' capabilities. ERP system implementation shapes the organizational business processes and the process has number of uncertainties. Since the system influences organizational business processes at first, organizations need to identify required features for targeted ERP systems and specify their organizational needs [Q].

\section{S14. For P14 lack of decent project management of ERP implementation}

In order to solve lack of decent project management obstacle on ERP system, organizations should take notice on the establishment of a project management unit. Then, project management team should be constituted, a project manager should be assigned, and adequate employees who have the knowledge of organizational business processes and advantages of an ERP system should be assigned to the project $[\mathrm{H}]$.

\section{S15. For P15 learning curve}

At the beginning of ERP system implementation project, training regarding ERP system is provided by ERP consultants to some system users. Therefore, some end users have chances to 
have training about ERP system's internal mechanisms and its effects on different business processes $[\mathrm{H}]$. Early system training of employees minimizes the complexity of ERP system for system users [G]. Also, in early stages, ERP consultants provide their knowledge to the system users. Well-trained system users are important to gain advantage from an ERP system and efficient use of it. Provided training simplifies the learning process and solves the problem of ineffective use of an ERP system. Increased experience in ERP system and transfer of the system knowledge to all system users in organization accelerates users' learning processes properly $[\mathrm{G}]$.

\section{S16. For P16 lack of in-house skills}

Organizations should have educated system users who have adequate knowledge about ERP system use, they cannot only rely on external ERP implementation teams and consultants [G]. The bidirectional knowledge transfer between ERP consultants and project team is valuable for effective usage of an ERP system. Increasing in-house skills reduces the vendor dependencies, increase users' involvement, and helps solving technical ERP problems [I]. Employees who have the knowledge about organization should also transfer their knowledge to ERP vendors in order to have a successful ERP system [G].

\section{S17. For P17 unbalanced project team}

ERP implementation team should consist of both IT people who have technical knowledge and business people who have the understanding of organization's business processes and operations. A balanced project team is critical for the success of an ERP system [J]. For the success of an ERP implementation, a mixture of an implementation team which includes both internal staff, system users and technical ERP consultants should be assigned to the project $[\mathrm{H}]$.

\section{S18. For P18 organizational misfit (cultural unity) (impact of cultural concerns on implementation and adaptation of ERP modules)}

In order to meet the requirements of organizations and solve the problem of organizational misfit of ERP systems, ERP vendors should provide more specific and divisional solutions that meet these organizations' expectations [A]. The understanding of non-European organization's business processes, organizational structure, and expectations provides an organizational fit between customer and ERP systems which increases the success of an ERP system and solves the problem of organizational misfit $[\mathrm{D}, \mathrm{M}]$.

\section{S19. For P19 lack of management support}

To overcome resistance, top management can resolve conflicts by organizing working hours, by designing new business processes according to their employees and by ensuring adequate training for new ERP system users and solve their problems. Therefore, continued support from top management throughout the project is important for the success and permanency of an ERP implementation project [J, M, CC]. Study [AA] states that enhancing of communication between management and system users within the organization expedites ERP adoption.

\section{S20. For P20 resistance to adoption of ERP}

User resistance is reduced by understanding the needs of system users by clarifying roles and responsibilities of system users properly and by providing top management support to solve confusion of users and mitigate the complexity of ERP system [G]. Clarified roles and responsibilities and top management support increase the expertise level of users that the success and the performance of on-premise ERP system are increased [G]. User resistance problem might be solved by creating awareness of an ERP system among the system users in early stages of ERP system implementation $[\mathrm{H}]$. Study $[\mathrm{U}]$ states that negativity of user resistance can be changed to positive side.

\section{S21. For $P 21$ relative invisibility}

Relative invisibility causes inconsistencies between technology and organizational expectations. From the primary studies, no clear and explicit solution direction could be derived.

\section{S22. For P22 loss of control due to decentralized decision-making}

The problem of decentralization of a decision-making process which causes major business risks can be reduced with the involvement of top management to the ERP implementation project, through the formulation of a proper project steering committee, the designation of a project sponsor, and by initiating the conduction of periodic internal audits during the project. Likewise, the risk of loss of control associated with decentralization of decision-making can be minimized [G].

\section{Discussion}

\subsection{Summary of research findings}

The problem of large upfront financial investment and the lack of change management of ERP modules were mentioned the most in the identified primary studies. This shows that the cost of ERP is still an important issue as well as the need for adapting the ERP system to the own context. Further, the lack of in-house skills, organizational misfit, and resistance to adoption of ERP were the secondly most mentioned problems. Obviously, the identified obstacles are not independent from each other but are related and interdependent. Based on the analyzed primary studies, we have also defined the diagram that shows the relations among these problems. For some obstacles, more than one type of solution was proposed, while other obstacles could have a single solution or even missing solution. For the obstacles, resistance compromising business process to align with generic ERP Modules (P8) and relative invisibility (P21), no clear solution directions were identified. Obviously, more research is needed to cope with these problems.

\subsection{Potential threats to validity}

Internal validity ${ }^{43,44}$ : We documented the search engines we used, defined our inclusion/exclusion criteria, and explained search strategy and search selection criteria. We also made forward snowballing and backward snowballing not to miss any relevant paper. 
Construct validity ${ }^{44}$ : We did not consider gray literature (white papers, blogs, etc.) as we wished to include only peerreviewed high-quality articles and proceedings in this study. To ensure the reliability, identified papers were reviewed by authors and disagreements were resolved by consensus.

Conclusion validity: The conclusions that we have drawn are also based on the identified primary studies. For justifying the results, all the authors have read the papers and in case of misunderstanding or disagreement, detailed analysis was carried out.

External validity: The primary studies have been carefully identified by following the steps of the adopted SLR protocol. Hence, we believe that the results of this study provide a proper insight into the obstacles and solution directions within the scope of on-premise ERP.

\section{Conclusion}

The selection and adoption of an ERP system for an organization is an important decision that requires detailed insight into the ERP system and the corresponding potential obstacles. For an organization that wishes to adopt ERP system, it is not easy to identify the obstacles and plan the transitioning accordingly. In this study, we have presented the results of an SLR to systematically compile and characterize the obstacles, describe the relations among these obstacles, and identify the solution directions. To the best of our knowledge, this article provides the first systematic review that has identified and compiled these obstacles.

The outcome of the SLR can be of benefit for both practitioners, that is, organizations that aim to adopt ERP systems, and researchers. For the practitioners, the identified obstacles as well as the solution directions can be an important input and guideline for the decision-making process. We believe that this study provides insight into and paves the way for further research. For the future work, we will focus on the open research problems and broaden the scope of the study to cloud-based ERP systems.

\section{References}

1. Chellappa RK, Saraf N. Alliances, rivalry, and firm performance in enterprise systems software markets: a social network approach. Inf Syst Res. 2010;21(4):849-71. doi:10.1287/isre.1090.0278.

2. Pollock N, Williams R. Moving beyond the single site implementation study: how (and why) we should study the biography of packaged enterprise solutions. Inf Syst Res. 2011;23:1-22.

3. Wu J-H, Shin -S-S, Heng MS. A methodology for ERP misfit analysis. Inf Manage. 2007;44(8):666-80. doi:10.1016/j. im.2007.09.001.

4. Shehab E, Sharp M, Supramaniam L, Spedding TA. Enterprise resource planning: an integrative review. Bus Process Manage J. 2004;10(4):359-86. doi:10.1108/14637150410548056.

5. Olhager J, Selldin E. Enterprise resource planning survey of swedish manufacturing firms. Eur J Oper Res. 2003;146(2):365-73. doi:10.1016/S0377-2217(02)00555-6.

6. Al-Ghofaili AA, Al-Mashari MA, Erp system adoption traditional ERP systems vs. cloud-based ERP systems, in: Innovative Computing Technology (INTECH), 2014 Fourth International Conference on, IEEE, 2014; Luton, UK. p. 135-39.

7. Poon P-L, Yu YT. Investigating ERP systems procurement practice: hong kong and australian experiences. Inf Soft Technol. 2010;52(10):1011-22. doi:10.1016/j.infsof.2010.04.003.

8. Zhu Y, Li Y, Wang W, Chen J. What leads to post-implementation success of ERP? an empirical study of the chinese retail industry. Int J Inf Manage. 2010;30(3):265-76. doi:10.1016/j.ijinfomgt.2009.09.007.

9. Xue Y, Liang H, Boulton WR. Information technology governance in information technology investment decision processes: the impact of investment characteristics, external environment, and internal context. Mis Q. 2008;67-96. doi:10.2307/25148829.

10. Shanks G, Parr A, Hu B, Corbitt B, Thanasankit T, Seddon P, Differences in critical success factors in ERP systems implementation in australia and china: a cultural analysis, ECIS 2000 Proceedings. Vol. 53; 2000; Vienna, Austria.

11. Bose I, Pal R, Ye A. Erp and SCM systems integration: the case of a valve manufacturer in china. Inf Manage. 2008;45(4):233-41. doi:10.1016/j.im.2008.02.006.

12. Duan J, Faker P, Fesak A, Stuart T, Benefits and drawbacks of cloud-based versus traditional ERP systems, Proceedings of the 2012-13 course on Advanced Resource Planning, Tilburg, The Netherlands.

13. Furneaux B, Wade MR. An exploration of organizational level information systems discontinuance intentions. Mis Q. 2011;573-98. doi:10.2307/23042797.

14. Li X, Chen Y. Corporate it standardization: product compatibility, exclusive purchase commitment, and competition effects. Inf Syst Res. 2012;23(4):1158-74. doi:10.1287/isre.1110.0412.

15. Xue $\mathrm{Y}$, Liang $\mathrm{H}, \mathrm{Wu}$ L. Punishment, justice, and compliance in mandatory it settings. Inf Syst Res. 2011;22(2):400-14. doi:10.1287/isre.1090.0266.

16. Elmonem MAA, Nasr ES, Geith MH. Benefits and challenges of cloud ERP systems - a systematic literature review. Future Comput. Inf. J. 2016;1(1-2):1-9. doi:10.1016/j.fcij.2017.03.003.

17. Klaus H, Rosemann M, Gable GG. What is ERP? Inf Syst Front. 2000;2(2):141-62. doi:10.1023/A:1026543906354.

18. Chung S, Synder C, Erp initiation - a historical perspective, AMCIS 1999 Proceedings. Vol. 76; 1999; Milwaukee, Wisconsin, United States.

19. Chen IJ. Planning for ERP systems: analysis and future trend. Bus Process Manage J. 2001;7(5):374-86. doi:10.1108/14637150110406768.

20. Davenport TH. Putting the enterprise into the enterprise system. Harv Bus Rev. 1998;76(4):106-16.

21. Stensrud E. Alternative approaches to effort prediction of ERP projects. Inf Soft Technol. 2001;43(7):413-23. doi:10.1016/S09505849(01)00147-1.

22. Ann Sykes T. Support structures and their impacts on employee outcomes: A longitudinal field study of an enterprise system implementation. Mis Q. 2015;39(2):473-95.

23. Morris MG, Venkatesh V. Job characteristics and job satisfaction: understanding the role of enterprise resource planning system implementation. Mis Q. 2010;143-61. doi:10.2307/20721418.

24. Liang H, Saraf N, Hu Q, Xue Y. Assimilation of enterprise systems: the effect of institutional pressures and the mediating role of top management. Mis Q. 2007;59-87. doi:10.2307/25148781.

25. Kitchenham B, Charters $S$, Guidelines for performing systematic literature reviews in software engineering, engineering, vol. 2

26. Kitchenham B. Procedures for performing systematic reviews. Keele (UK): Keele University; 2004. Vol. 33. p. 1-26.

27. Mian P, Conte T, Natali A, Biolchini J, Travassos G, A systematic review process for software engineering, in: ESELAW'05: 2nd Experimental Software Engineering Latin American Workshop, 2005; Uberlândia, Brasil.

28. Vallon R, da Silva Estacio BJ, Prikladnicki R, Grechenig T. Systematic literature review on agile practices in global software development. Inf Soft Technol. 2018;96:161-80.

29. Rowe F. What literature review is not: diversity, boundaries and recommendations. 2014. doi:10.1057/ejis.2014.7.

30. Alzoubi YI, Gill AQ, Al-Ani A. Empirical studies of geographically distributed agile development communication challenges: A systematic review. Inf Manage. 2016;53(1):22-37. doi:10.1016/j.im.2015.08.003.

31. Mahmood S, Anwer S, Niazi M, Alshayeb M, Richardson I. Key factors that influence task allocation in global software development. Inf Soft Technol. 2017;91:102-22. doi:10.1016/j. infsof.2017.06.009. 
32. Li L, Bissyande TF, Papadakis M, Rasthofer S, Bartel A, Octeau D, Klein J, Traon L. Static analysis of android apps: A systematic literature review. Inf Soft Technol. 2017;88:67-95. doi:10.1016/j. infsof.2017.04.001.

33. Dikici A, Turetken O, Demirors O. Factors influencing the understandability of process models: A systematic literature review. Inf Soft Technol. 2018;93:112-29.

34. Catal C, Diri B. A systematic review of software fault prediction studies. Expert Syst Appl. 2009;36(4):7346-54. doi:10.1016/j.eswa.2008.10.027.

35. Zhang H, Babar MA. Systematic reviews in software engineering: an empirical investigation. Inf Soft Technol. 2013;55(7):1341-54. doi:10.1016/j.infsof.2012.09.008.

36. Uzun B, Tekinerdogan B. Model-driven architecture based testing: A systematic literature review. Inf Soft Technol. 2018;102:30-48.

37. Zhang $\mathrm{H}$, Babar MA, Tell P. Identifying relevant studies in software engineering. Inf Soft Technol. 2011;53(6):625-37. doi:10.1016/j.infsof.2010.12.010.

38. da Silva FQ, Santos AL, Soares SC, Franca ACC, Monteiro CV, A critical appraisal of systematic reviews in software engineering from the perspective of the research questions asked in the reviews, in: Proceedings of the 2010 ACM-IEEE International Symposium on
Empirical Software Engineering and Measurement, ACM, 2010; Bolzano-Bozen, Italy. p. 33.

39. Dieste O, Padua AG, Developing search strategies for detecting relevant experiments for systematic reviews, in: empirical software engineering and measurement, 2007. ESEM 2007. First International Symposium on, IEEE, 2007; Madrid, Spain. p. 215-24.

40. Kitchenham B, Brereton OP, Budgen D, Turner M, Bailey J, Linkman S. Systematic literature reviews in software engineering - a systematic literature review. Inf Soft Technol. 2009;51 (1):7-15. doi:10.1016/j.infsof.2008.09.009.

41. Van Der Linden F, Bosch J, Kamsties E, Kansala K, Obbink H, Software product family evaluation, in: International Conference on Software Product Lines, Springer, 2004; Boston, MA. p. 110-29.

42. Pollock N, Hyysalo S. The business of being a user. Mis Q. 2014;38(2):473-96. doi:10.25300/MISQ/2014/38.2.07.

43. Wohlin C, Runeson P, Host M, Ohlsson MC, Regnell B, Wessl'en A. Experimentation in software engineering. Springer Science \& Business Media; 2012; Berlin/Heidelberg, Germany.

44. Garousi V, Felderer M, Hacaloglu T. Software test maturity assessment and test process improvement: a multivocal literature review. Inf Soft Technol. 2017;85:16-42. doi:10.1016/j.infsof.2017.01.001. 